Arqueología y Sociedad,

$N^{\circ} 16,2005$

\title{
El Formativo de Pacopampa. Un ensayo de interpretación*
}

Peter Kaulicke

Aunque últimamente aparecieron varios trabajos sobre el Formativo norandino y la zona de Pacopamapa (Rosas y Shady 1970 a,b, 1974; Fung 1975, Kaulicke 1975), se agregan estas notas como un ensayo interpretativo. Se trata de verificar algunas sugerencias acerca del funcionamiento y la organización social en el Formativo ejemplificándolo en el caso de Pacopampa, que representa algunas características que podrían tener mayor implicancia.

* Publicado originalmente por el Seminario de Historia Rural Andina, Lima, 1976. 


\section{El Formativo de Pacopampa. Un ensayo de interpretación}

Básicamente no me parece posible llegar a interpretaciones concluyentes ni utilizando exclusivamente conceptos ecológico-culturales ni limitándose a la "objetividad arqueológica". Uno de los auxiliares potenciales es el análisis de motivos figurativos, una técnica muy usada y frecuentemente malentendida en la arqueología andina. Otro es la etnohistoria, que es el único medio que puede comunicar el sentido de los símbolos y valores de un sistema que es distinto al nuestro y cuyo significado no se deduce usando la lógica causal. El resultado, sin embargo, siempre queda dentro del margen de la interpretación. Existe sólo la gradación de la probabilidad. Bajo este aspecto quiero analizar algunas ideas expresadas ya en al literatura respectiva o como resultado de los trabajos de campo llevados a cabo en la zona de Pacopampa.

Necesariamente hay que repetir algo de lo ya publicado (Kaulicke 1975, s.f) para tener una idea coherente de la situación particular del valle de Pacopampa en el Formativo. Las observaciones se basan en excavaciones y recorridos de campo en dos temporadas en los años de 1973 y 1974.

La zona en discusión está situada en el departamento de Cajamarca, provincia de Chota, distrito de Querocoto. El acceso se efectúa por la carretera Chiclayo-Chota, tomando un desvío antes de llegar a Huambos. La costa comienza a unos setenta kilómetros hacia el Oeste, en línea recta. Hacia el Este, más o menos la misma distancia da con el Marañón. El valle de Pacopampa está ubicado en la ribera oeste del río Chotano que, unos treinta kilómetros más hacia el Norte, se reúne con el Huancabamba para formar el Chamaya, el cual, a su vez, afluye al Marañón.

La zonificación ecológica es clara y comprende:

1.- La Playa, a la altura del Chotano (1000 a 1200 m.s.n.m.), con temperatura alta, agricultura inestable por las fluctuaciones en los caudales del río. Hay "bosques” de caña brava(Gynericum sagitatum), pocos arbustos y árboles (faike, mosquera).

2.- El Temple( 1200 a 2000 m.s.n.m.), una especie de meseta inclinada hacía el río, intensivamente cultivada, cálida, de frutos agrícolas subtropicales y árboles con gramíneas que forman una sabana con faike (Acacia macrantha), palo de balsa (Ochroma piscatoria) y varios arbustos.

3.- La Quechua (2000 a 2400 m.s.n.m.), bosque montano húmedo bajo donde actualmente se encuentran las poblaciones mayores y la mayoría de las zonas agrícolas que producen arracacha, maíz y frejoles principalmente.

4.- La Jalca (24000 a 2800 m.s.n.m.), bosque húmedo montano alto que en su mayoría no está habitado.

Con la altura, la humedad también sube gradualmente, de 50 a $10 \mathrm{~mm}$, hasta más de $150 \mathrm{~mm}$ como media anual, mientras que la temperatura baja de $21^{\circ}$ a $11^{\circ}$ (datos de Medina Valderrama 1961, cap. VI). La irregularidad pluvial en su distribución anual y la intensidad son nocivas para la agricultura, aunque los suelos en la regla son buenos, pero requieren de irrigación artificial sobre todo en la parte baja(Temple).

En base a las excavaciones efectuadas en el sitio de Pandanche (situado en el Temple) podemos subdividir el Formativo en tres grandes fases que llamamos $\mathrm{A}, \mathrm{B}$ y $\mathrm{C}$, cada una con sus subfases.

Una fase antes de A podría representar un Arcaico Final, aunque no está muy bien definida ni por una industria lítica diagnóstica ni por estructuras. Las únicas evidencias que podrían justificar la separación de A son dos fogones y la ausencia de cerámica. Esta fase se desconoce en los demás sitios.

- La fase A también carece de estructuras debido a lo limitado de la excavación. Futuras investigaciones tendrán que esclarecer el patrón de asentamiento. La cerámica es diagnóstica y novedosa. Hay ciertas influencias del área selvática por la forma de las ollas de perfil compuesto y la 
distribución de la decoración de tiras sobrepuestas con impresiones y brochado. Además hay impresiones de conchas, incisiones unguladas, zonas alternantes sin preparación alguna de la superficie, de color bruñido diligente. Quizá sea posible una subdivisión de esta fase como sigue:

- A I: con pocos fragmentos hallados en capas inmediatamente encima de aquellas sin cerámica. Son tazas pequeñas con pasta porosa, bordes biselados y superficies bruñidas sin decoración, el color es blanco humo con manchas de cocción.

- A II: sería básicamente la cerámica ya descrita.

- A III: tiene influencias desde afuera. Otros indicios de contactos con la costa son conchas marinas ornamentales (Astraea buschi). Hay indicios de una transición como incisiones cortantes entrecruzadas, puntuaciones en ollas pequeñas cerradas pulidas con decoración en áreas alisadas y puntuaciones entre triángulos. Además hay otra cerámica con líneas cortantes muy finas y profundas (Pandanche Peinado) en conjuntos verticales $\mathrm{u}$ ondulados (especialmente algunos fragmentos grandes encontrados por Daniel Morales en una excavación posterior en el mismo sitio que representan ollas pequeñas aplanadas con bordes cortos evertidos (comunicación personal). Falta más material para entender bien si se trata de una transición o de una ruptura clara hacia la fase B. Más probable es el comienzo de otra tradición cerámica que tal como A debe tener sus orígenes hacía el este de la zona en discusión. El Pandanche Peinado también aparece muy tardíamente en términos de la fase A, llegando a tener más frecuencia en B I, aunque su porcentaje siempre está muy debajo del 10\%. El buscar material comparativo en la literatura arqueológica para la fase A resulta muy difícil porque se limita en la regla solo a semejanzas genéricas. Si bien hay algunas evidencias en el Tutishcainyo, como la forma de las vasijas de perfil compuesto y la distribución de decoración en paneles debajo del borde y encima del ángulo de carenación, hay otras características que son dis- tintas, lo que también vale para Guañape. Más tempranamente surgen muchos de los rasgos definitivos de A en la tradición Valdivia en su configuración tardía, donde encontramos las tiras sobrepuestas, el brochado, el peinado y algunas formas semejantes (Valdivia Co 6 de Betsy Hill). Rasgos semejantes también se encuentran en la sierra del Ecuador (Bennett 1946, fig. 1200 y Myers 1976, fig. 2k-1). Posiblemente estas semejanzas se concreten en el futuro puesto que el conocimiento sobre Valdivia ha crecido enormemente en los últimos años, lo que vendrá a esclarecer los posibles contactos y la gran discrepancia temporal que existe aún entre las dos áreas culturales. En cuanto a la aparición de la cerámica en Imbabura(Ecuador), cerámica semejante al Pandanche Peinado, se ha correlacionado con Machalilla (1400-1100 a.C.), encontrando este tipo también en la península de Santa Elena, aunque se diferencia por tener engobe blanco (Myers 1976, 355-356). Parece por estas razones también más probable que Pandanche Peinado pertenezca a la fase $B$.

La Influencia del Ecuador puede haber llegado al Perú en varias rutas diferentes. La cerámica típica para B, el inciso cortante se encuentra en forma semejantes también en Cuenca(véase Bennett 1946 y Colliere y Murra 1943). Ésta se da en Pacopampa tal como en Bagua, en el departamento de Amazonas. En el primero de los sitios, más tarde, aparecen rasgos relacionables con "Chavín" algo que es ausente en Bagua. En este último, sin embargo, se ven rasgos muy relacionados a Machalilla (Shady 1971, lám. 9, fig.3), una forma desconocida en Pacopampa, lo que ocurre en la fase B II. La completa ausencia de rasgos "Chavín" en la montaña parece ser significativa.

La subsistencia está basada en la agricultura puesto que huesos de animales son escasos (venado, cuy, vizcacha); y cierta cantidad de caracoles terrestres (Bulimulus), cuya presencia en las capas superiores aumenta, hace suponer que se trata de parte de la dieta. No hay mayores evidencias de implementos de cacería. 
Posiblemente algunas piedras redondeadas servían para este fin mediante el uso de hondas. Las semillas carbonizadas presentes, a veces en considerable cantidad, sin embargo, son las mejores evidencias e indican el cultivo de frijoles y posiblemente maní.

La industria lítica no es muy diagnóstica. Hay lascas denticuladas, pequeñas piedras de cuarzo con pulidores de cerámica y cuchillos de dorso natural con pocos retoques de uso. La materia prima es sílex, andesita, cuarcita y cuarzo.

La fase B se caracteriza por la cerámica llamada Inciso Cortante, con platos pulidos en el interior y mates en la superficie exterior con motivos decorativos geométricos. En algunos casos se nota pintura post-cocción en área. Además hay vasijas como jarros pequeños con borde evertido incidido. El porcentaje de la cerámica decorada es alto, tal como en la fase A. Una cerámica que siempre aparece sin decoración, tiene paredes muy delgadas, superficie externa áspera, superficie interna alisada de cuerpo probablemente globular o subglobular y bordes evertidos (diámetro 20 a $30 \mathrm{~cm}$ ). En el fondo llevan con cierta frecuencia restos carbonizados. Posiblemente se trata de recipientes para algún líquido (chicha?).

La arquitectura es conocida solo por un muro de piedras muy grandes irregulares (Kaulicke 1975, lám. VI). Parece que el complejo Pacopampa se inicia en esta fase. Excavaciones futuras son necesarias para determinar el patrón de asentamiento.

La subsistencia sigue semejante a la de la fase A, pero la industria lítica demuestra algunas modificaciones que son notables. Muchas esquirlas de silex o cuarcita que por la regla no exceden los $2 \mathrm{~cm}$ de largo, de contornos irregulares y sin retoques, hacen pensar en un uso especial, puesto que ningún artefacto de este material se ha encontrado en asociación fuera de núcleos muy pequeños. Existe la posibilidad de que estos objetos fueran ensartados en tablas de madera para pelar la yuca, planta que actualmente crece en el Temple. Como se sabe, aquella es una planta que casi tiene las mismas carac- terísticas que las plantas de almacenaje, puesto que permite siembras y cosechas casi continuas. Es posible que ella sea la base económica en esta fase lo que explicaría el auge de esta tradición en la subfase B II, en la cual se nota una serie de tipos cerámicos atípicos y foráneos con la representación de felinos y cerámica modelada, objetos de piedra pulida y conchas marinas. Este auge debe ser reflejo de una situación semejante en Pacopampa que cuenta además con otros objetos suntuarios (véase más adelante).

La tradición B sigue existiendo en la Fase C, justificando otra subdivisión en un B III, aunque ya en forma debilitada. C se subdivide en C I y C II. Aparecen muchos nuevos tipos de cerámica de varias zonas, a veces lejanas, del área. Es la culminación de la historia del complejo Pacopampa que trae consigo muchas innovaciones decisivas. Fuera de la introducción de nuevos tipos cerámicos influenciados por la cerámica Chavín en pocos ejemplares y de otras zonas, hay que anotar un cambio en la agricultura con la introducción del maíz (comprobado por granos carbonizados junto con frejoles), de la irrigación, de la piedra tallada en el uso de la construcción en graderías, plazas hundidas y el uso del mortero desconocido hasta entonces. Hay indicios más claros y definitivos de la textilería (piruros de piedra y cerámica o de fósiles y agujas de hueso), vasos de piedra y anzuelos de concha marina. De allí quizá también pueda datar la introducción del perro, al menos en Pandanche aparece en forma de "ofrenda".

En C II hay un notable declive anotado por nuevos tipos cerámicos que están en relación con construcciones en lajas de piedras irregulares y con canales semejantes a los que encontró Rosa Fung en Pacopampa (1975, Plano IV, Canal A). La cerámica es mucho más gruesa, con pocas decoraciones, entre las cuales destacan bordes engrosados pintados de rojo, cuellos con caras antropomorfas y cerámica estriada con mucha semejanza a una cerámica conocida de Bagua (Fase El Salado, Shady 1971, lám. 7 j-1, fig. 9-10, compárese con Kaulicke 1975, lám. xxi). De 
esta manera se reinician influencias del Este, las cuales aparentemente no se aprecian tanto en el mismo Pacopampa, hecho que se podría interpretar quizá como indicios de desintegración. La cerámica incisa cortante está ausente y finalmente la cerámica Cajamarca se sobrepone en prácticamente todos los sitios formativos reconocidos.

Antes de comenzar con la explicación de la distribución espacial y sus cambios durante el Formativo, quisiera enfocar el uso actual de la zona. La zona cultivada comienza hacia el norte con el valle pequeño de Querecotillo (Cutervo), sigue con Pacopampa y Querocoto para prolongarse hacia el Sur, en alturas más elevadas, hasta Cochabamba, siempre en el margen oeste del Chotano (a lo largo de $29 \mathrm{~km}$ ). La mayoría de los asentamientos más poblados se ubican en la franja entre el Temple y la Jalca, mientras en el mismo Temple hay una serie de pequeños establecimientos . Según Medina Valderrama (1961, pp. 184-185) la distribución sería la siguiente: menos de 50 hasta 100 habitantes están representados con un porcentaje de 59.0\%, 100 a 200 habitantes con $26.23 \%$, y 200 a más de 500 habitantes con $14.75 \%$. La gran mayoría de los últimos está cerca del límite de los 2400 m.s.n.m.

La subdivisión de las zonas ecológicas es como sigue: Playa con cerca de $4.5 \mathrm{~km}^{2}$ ó 6\%, Temple con $30 \mathrm{~km}^{2}$ ó 39.7\%, Quechua con 24 $\mathrm{km}^{2}$ ó $31.8 \%$ y la Jalca con $17 \mathrm{~km}^{2}$ ó $22.5 \%$, lo que da un total de $75.5 \mathrm{~km}^{2}$. Hacia el Sur tenemos casi la exclusividad de la Quechua con $66 \mathrm{~km}^{2}$.

En el Formativo la distribución es algo diferente. Ni en la Jalca ni en la Playa se han notado sitios de esta época: tres sitios están situados en la Quechua y diez en el Temple (Kaulicke 1975, lám II, pp. 56-57; n.d.b.). El sitio principal Pacopampa está ubicado en la Quechua (2140 m.s.n.m.). Tomando como punto de referencia el centro ceremonial (lo que es justificado por lo menos para la fase $\mathrm{B}$ y $\mathrm{C}$ ) se notan dos semicírculos formados por sitios hacia el Este. Los primeros están a una distancia de entre 3 y $4 \mathrm{~km}$. Algunos de ellos datan desde el Formativo Temprano
(Pandanche y quizá Yuyuampampa), pero todos llevan fuertes evidencias del Formativo Medio (B) y se encuentran cerca de las quebradas que llevan agua. De estos cinco sitios en el Temple, tres tienen construcciones y el sitio más extenso (también con plataformas y una altura de cerca de $20 \mathrm{~m}$ ) es Pandanche. En los dos sitios más al Sur no se ha reconocido arquitectura. Cabe notar que todos ellos se sitúan en el límite superior del Temple.

En el Formativo Tardío evoluciona este sistema notablemente, agregando otro semicírculo más hacia el Este, que se sitúa en el límite inferior del Temple, controlando de esta manera gran parte de este piso ecológico. Sólo uno de estos sitios se caracteriza por tener arquitectura, mientras los tres sitios de la Quechua tienen estructuras. El sitio principal Pacopampa se ha convertido en un centro con un patrón complejo que sigue básicamente los contornos de las colinas. $\mathrm{Su}$ posición está orientada casi exactamente hacia los puntos cardinales con un eje largo en dirección Este-Oeste y dos ejes verticales de Norte a Sur. El centro ceremonial está en el cruce del eje hacia el Oeste. En este eje vertical se sitúa también Cochecorral con estructuras semejantes al propio "templo". Este desarrollo ha sido posible básicamente por la introducción de la irrigación artificial mediante "cochas" como boca-tomas y canales subterráneos construidos con piedras que fueron muy necesarios para el cultivo nuevo.

El maíz podría haber mantenido una población mayor que la de B. Pero cabe notar que los sitios de B ya están elaborados explotando el Temple mediante técnicas menos avanzadas. Fue entonces básicamente esta zona ecológica la que fue explotada en el Formativo en un área que representó hasta un tercio de la zona del cultivo actual. Si aceptamos un área de $24 \mathrm{~km}^{2}$ (lo que incluye lo circunscrito de todos los sitios del Formativo,) vemos que hasta $14 \mathrm{~km}^{2}$ fueron cultivados en el Temple, mientras es muy difícil calcular la explotación de la Quechua. Si existió debe haberse encontrado hacia el norte del sitio 
principal, pero casi con seguridad no excedió los $6 \mathrm{~km}^{2}$.

Se nota, entonces, que el predominio de la zona del Temple es muy obvio, lo que hace pensar que la ubicación del sistema Pacopampa no fue casual. Según Medina Valderrama (1961, p. 181) es la parte más baja del río Chotano. Forma entonces un nicho ecológico. Otro punto de importancia crucial es el hecho de que se trata del único lugar donde se puede practicar la agricultura, sin recurrir al sistema de deforestación y quema, aunque es posible que lo practicaron también, si bien en forma reducida. Esta última práctica posiblemente comenzó en 3, lo que sugiere la ubicación del sitio de Pacopampa, Pandanche, en los inicios. Probablemente fue el sitio principal que sólo lentamente se desplazó hacia Pacopampa.

En realidad precisamente este crecimiento del sitio central es algo problemático porque no es explicable solamente por el proceso que se acaba de describir. La acumulación de bienes suntuarios y la arquitectura monumental no caben necesariamente en el marco ecológico.

La población actual de la zona que cubre el Formativo estará alrededor de 4 mil habitantes, mientras un cálculo razonable para la época en discusión debería estar entre los mil a mil quinientos, como máxima podría sostener quizá dos mil habitantes (para el Formativo Tardío).

Lamentablemente no contamos hasta el momento con suficientes fechados de C-14 para darnos una idea de la extensión temporal del Formativo en esta zona. Para los comienzos de la fase $B$ existe un fechado de $1835 \pm 100$ a.C. $y$ Reichlen parece tener otro de 1900 a.C. (Comunicación personal de Ramiro Matos), pero no se sabe mucho acerca de las circunstancias ni de la extracción ni la posición estratigráfica de las muestras. Si fuera aceptable esta posibilidad tendríamos una antigüedad considerable, puesto que la fase A se colocaría ya en el segundo milenio antes de nuestra era. En otra ocasión comparé la técnica de construcción del centro ceremonial con la de Áspero (Kaulicke s.f.), que aunque pertenece al Precerámico Final, demuestra marcadas similitudes con Pacopampa sólo que este último es mucho más grande. La monumentalidad del sitio en ambos casos se basa en la altura percibida, la que no es la altura real. Esto resulta en una reducción notable de la labor efectuada que contrasta con otras estructuras conocidas del Formativo las cuales se erigieron en forma enteramente artificial.

Pero aunque se piensa en un desarrollo relativamente lento, la "explosión" en las fases B II y C I no son explicables tampoco por este argumento.

Es algo difícil comparar estas evidencias con las de otras zonas, sobre todo en lo que concierne a la organización interna. En la costa central, la zona más estudiada, se tiene una serie de centros ceremoniales en forma de "U" que se erigieron ya mucho antes del surgimiento de Chavín, en algunos casos ya desde el Precerámico Final (véase reseña reciente de Ravines 1975). El área circunscribe los valles de Lurin, Rimac, Chillón y Chancay. Más al norte, desde Casma, Santa, Huarmey, Pativilca hasta Supe, se encuentran estructuras con pozos circulares hundidos (Williams 1972). Cabe la posibilidad de que en Pacopampa también haya existido uno de estos pozos grandes. Una "laguna" que se rellenó con piedras, haciendo algo difícil su percepción en la superficie, está situada delante de la estructura principal.

Fuera de los centros ceremoniales, cuya función como tales se ha comprobado en las excavaciones recientes en Garagay (Ravines 1975, Ravines e Isbell 1975) y que durante el Formativo Tardío ya parecen haber perdido su influencia, existen pequeños pueblos en las partes bajas y medias de los valles y pueblos grandes de pescadores en el litoral (Ancón y Curayacu). El patrón parece disperso y no cambia mucho en el momento de la introducción de elementos Chavin, pero tiene un efecto resultante en pueblos con cientos de cuartos ordenados alrededor de plazas en un patrón rectangular (Rimac, Patterson 1971, pp. 31-33). El centro ceremo- 
nial que probablemente tuvo más duración fue Garagay (op. cit., p. 36). Como explican Ravines e Isbell (1975, pp 266-271), no hay evidencias de un desarrollo urbanístico ni que un centro tenga sus respectivos asentamientos públicos sino que existen algunos centros ceremoniales en cada valle que sugieren ser contemporáneos. No hay evidencia clara de una estratificación social compleja, sino más bien se encuentra en un estado de transición. Para la Sierra hay menos evidencias, pero también allí hay centros ceremoniales y pequeños pueblos sobre todo en zonas donde se puede suponer el surgimiento de una agricultura avanzada.

\section{Funciones de centros ceremoniales}

Si bien notamos claramente la importancia de edificios ceremoniales para el Formativo, no existen mayormente intentos de interpretaciones acerca de su posible función. Este hecho está relacionado con un cierto descuido en el tratamiento de la religión prehispánica a pesar de que existen numerosos documentos acerca de este tema (archivos arzobispales, inquisición, etc.). Hay sobre todo un aspecto que quiero tratar porque podría tener relevancia para sistemas religiosos tempranos: los oráculos. Parece que bajo el incanato hubo básicamente un oráculo de importancia, Pachacamac. Pero fuera de este existían muchos otros de alcance regional: en Chinchaycama (Cieza de León 1947, cp. LXXIV, P. 423), donde los incas reemplazaron este por un templo del Sol sin poder desdoblar la adoración antigua, Cajamarca (op. cit., cap. LXXVII, p. 42), Huamachuco (Apo Catequil, Agustinos 1918, p. 23), Munipuindo (op, cit. P. 29). Huánuco (Cieza de León 1947, cap. LXXX, p. 429). Huaylas (op. cit., cap. LXXXXIII), Wariwillka (op. cit., cap. LXXXIV, p. 432), Apurímac (op. cit., cap. XLI, p. 437), Contisuyo (op. cit., cap. XLIV, p. 438), Chucuito (op. cit., cap. L, p. 443), Vilcanota, Curicancha, Coropuna, Aperahua (Cieza de León 1967, pp. 95-99), Pacopampa (Cobo 1964, t. II, cap. XVIII) y Choque Hispana (Medina 1921, pp. 89.
90). Posiblemente todas las "guacas" que tenían una importancia más que local podrían considerarse como oráculos, una posibilidad que sugiere Cieza, y en forma menos precisa Albornoz (1967), quien da una lista muy larga de lugares sagrados en todo el Tahuantinsuyo sin especificar bien la función de cada uno. Muchas veces aparecen que son pacarinas (lugares de origen). La razón por la cual oráculos no están mencionados con mucha frecuencia en las crónicas (fuera de Pachacamac) y otros documentos tratando estos aspectos podría explicarse porque muchos de ellos fueron reemplazados por orden de los Incas, quienes oprimieron decididamente creencias antiguas por una adoración de sus propias personas en función de control. Efectivamente, muchas huacas tienen como "ídolo" a un ser antropomorfo que requiere todos los privilegios de señores, ropa fina, vasos de oro, mujeres, etc., pero probablemente este no es el tipo de veneración original. Más importantes fueron las pacarinas, quizás como símbolo de unificación étnica (hasta de parentesco), centro mítico y lugar de mayor potencialidad mágico-religiosa, lo que no excluye la función de oráculo también.

Veamos la manera de función de estos oráculos. Uno de los informes más tempranos es el de Hernando Pizarro (1921, pp. 167 ss.) de 1533: "Para entrar al primer patio de la mezquita, han de ayunar veinte dias para subir la patio de arriba, han de ayunar un año. En este patio de arriba suele estar el obispo cuando suben algunos mensajeros de caciques que han ya ayunado su año a pedir al dios que les de maíz y buenos temporales, hallan el obispo cubierta la cabeza y asentado. Hay otros indios que llaman pajes del dios. Asi como estos mensajeros de los caciques dicen al obispo su embajada, entran aquellos pajes del diablo dentro a una camarilla, donde dicen que halan con el e aquel diablo les dice de que esta enojado de los caciques e los sacrificios que se han de hacer, e los presentes que quiere que le traigan". (op. cit. pp.176 177). Cieza dice lo siguiente (1947, cap. LXXII, pp. 421 22): "Y dicen que mas que delante de la figura de este demonio sacrificaban número de animales y alguna sangre 
humana de personas que mataban y que en sus fiestas, las que ellos tenían por mas solanos, daban respuestas y como eran oídos, las creían y tenían por de mucha verdad... y es fama que habían junto al templo muchos y grandes aposentos para los que venían en romería y que a la redonda del no se permitía enterrar ni era digno de tener sepultura, sino eran los señores o sacerdotes o los que venían en romería y a traer ofrendas al templo. Cuando se hacían las fiestas grandes del año era mucha la gente que se juntaba, haciendo Sus juegos con sones de instrumentos de música que ellos tienen". Los agustinos hablan algo semejante acerca de Apo Catequil (1919, pp. 22 23). Más interesante en esta relación es una descripción muy detallada acerca de semejantes prácticas (p. 17 19): "y la manera que tenían general, cuando querían hacer su mocha o adoración, era que hacían una almohada muy labrada de muchos colores y labores, y que para las guacas que no eran las principales, no los hacian tan galanes, y hacian un castillo o canastillo de verguillas muy blancas y tejían con lana, y era por baxoancho y en lo alto angosto, y en lo angosto que quedase dentro de una concavidad para no poner la guaca, y a este castillo vestían como personas, de muy lucidas y ricas camisetas de cumbi.... con sus mantos y llautos... muy ricos con argentería y chapas de oro y plata y con plumas muy calanas de diversas maneras, poniánles sus chuspas llenas de coca, y ponianles guaracas.....y aqui venia el demonio y se metía en aquel castillo que vestido estaba y alli hablaba con los hechiceros solamente. Cuando el hechicero hacia de entrar a hablar a la guaca, ponían una manta muy pintada y muy oronda como velo, para que el pueblo no viese al hechicero en tanto aquél hablaba a la guaca, y cuando la hablaba respondía la guaca recio para que el pueblo la oyese y lo que pedían y quería dar....Y después de oída la respuesta y engañoso oráculo... mataban cuyes y ovejas, y la sangre a la guaca y de aquí casi toda la ropa que se sacó de las gaucas y se quemó mucha, estaba toda manchada de sangre, y muy ensangrentada. Y después de ofrecida la sangre guisaban a su modo aquellas carnes y comían todas, y el hechicero para sacrificar ha de ir ayuno, que en tres días no ha de comer sal ni ají, ni ha de dormir con su mujer. Después que ha comido, el sirve el hechicero a la guaca de agua o chicha, y alli luego hacían grandes borracheras y taguis". Con frecuencia se menciona la riqueza en oro y plata que caracterizaba las guacas, aunque en el caso de Cieza de León, Carlos Araníbar (1967, prólogo, p. XXXVI XXVIII) critica lo exagerado de sus notas en este respecto. Pero este cronista concuerda básicamente con la mayoría de los otros.

Lo fundamental, entonces, en la función del oráculo, fue la comunicación de algún deseo formulado que había de pagar. Esto significa que fue un ritual en el cual se presenta una reciprocidad aunque en forma negativa que resulta, por el otro lado, en una acumulación de bienes a servicio de los especialistas del culto. En un nivel más bajo tenemos las masas menos privilegiadas que acuden al sitio en forma de peregrinación, aunque no tienen acceso al santuario mismo. Probablemente el carácter económico detrás de estos movimientos fue algo diferente al de la clase dominante. En las peregrinaciones actuales (Sallnow 1974, pp. 123-139) un motivo muy importante es la ganancia de prestigio con el cual alcanzan un nuevo status, lo que sucede a base del intercambio de bienes con acciones (patrónbailarines).

Pero hay otra faceta más que es de singular importancia. Un concepto común es la multiplicación de las huacas principales en hijos. Santillán (1968, p. 111) habla de cuatro hijos de Pachacamac, una en Mala, otro en Chincha (probablemente Chichaycama), otro en Andahuaylas: "Y asi hizo las dichas cosas (Topa Inga) y de aquellas huacas fueron multiplicando muchas más, porque el demonio, que por ellos hablaba, les hacia hacer nuevas casas y adoraciones a los que creían que procedían de las dichas guacas, y a todos tenían por sus dioses. Uno adoraban como a hombres y a otros como a mujeres, y aplicaban sus devociones cada uno para un genero de necesidad a unas iban para que hiciesen llover, a otras para que las mujeres se empreñen, y asípara las demás cosas". María Rostworowski (1972, pp. 42, 43) sugiere que el culto de Pachacamac fuese mucho más 
difundido aún (hasta la Selva y el Cuzco), y según Pachacuti (1968, p. 309) hasta Chan Chan. Algo semejante relatan también los agustinos con respecto a Catequil. M. Rostworowski piensa que fue una forma de proselitismo, como "un tipo de archipiélagos religiosos" con marcados intereses económicos, y expresa la hipótesis que el papel de Pachacamac en el Horizonte Medio podría haber contribuido a la expansión del idioma quechua.

Para poder garantizar sus bases económicas estos oráculos dominaban las zonas que les proveían con lo requerido. En Mala vivía una mujer de Pachacamac, en una región muy importante para la plantación de la coca (Rostworowski 1972, p. 41). En Ávila (1966, cap. 22, p. 127) se hace mención a las llamas, las cuales se criaban especialmente para los sacrificios en Pachacamac en la sierra de Huarochirí. Nosotros hemos podido ver la influencia de sitios del Horizonte Medio Temprano en la sierra de Canta (Kaulicke, 1975 b).

Tenemos, entonces, como modelo el sitio principal de aspecto mágico - religioso que dominaba un territorio relativamente restringido, abarcando la costa - una mujer de Pachacamac, Urpay Huachac, es diosa de los peces (Rostworowski 1973, 1975) - hasta la sierra alrededor del valle de Lurín. Este territorio sirvió de base para el mantenimiento del aparato relacionado con el culto y del personal permanente ocupado con el funcionamiento del mismo. Este aparato, a su vez, hace ingresar bienes de lucro que incide en su propio crecimiento. A partir de haber llegado a un punto de culminación se hace preciso la distribución más amplia, lo que se logra mediante la instalación de otros centros desligados territorial y hasta cierto punto ideológicamente del centro nuclear.

Pachacuti (1968), en el afán de demostrar su buena cristianidad, llena su crónica con las controversias que los incas habrían tenido con las guacas pero deja entrever algo que es de mayor interés. Las conquistas se justifican con la destrucción o incorporación de huacas ajenas en su propio panteón y el botín proviene básicamente de aquellas. Como ya queda mencionado, los incas reemplazaron frecuentemente las huacas autóctonas por imágenes de sus propias personas a las que habían que rendir un culto semejante al menos en cuanto a las ofrendas que constituían lo que se podría llamar tributo especial. Los especialistas del culto también fueron reemplazados por yanacuna, únicamente responsables al propio inca (comunicación personal de María Rostworowski). Los Tacana de la selva boliviana mantienen este mismo nombre para sus chamanes hasta la actualidad (Furst 1968, p. 159).

Esta actitud nos da la contraparte de este modelo que por su propio carácter provoca actividades bélicas vestidas en luchas ideológicas a las cuales sucumben aquellos integrantes cuya adaptación a sistemas diferentes al suyo es deficiente.

En el caso de Pachacamac su existencia preincaica está comprobada con una duración al parecer continua de más de mil años (Jiménez Borja y Bueno 1970), aunque su función anterior al Incanato no está muy clara debido mayormente a la falta de excavaciones más extensas. Sin embargo, sabemos de los crónicas que el culto de Pachacamac y su existencia como oráculo tiene un origen mucho más allá de la influencia incaica. Ya en el periodo de desarrollos regionales existen estructuras que Jiménez Borja y Bueno (1970) interpretan como templos. Además existen calles pre-incaicas, según los autores, orientadas hacia los puntos cardinales y que convierten el sitio en algo que es de mucha importancia para la ubicación geográfica mítica, "el centro del mundo" (Eliade, 1974. cap. I).

Para el Formativo algunos autores propusieron esta función para los centros ceremoniales, sobre todo los del mismo Chavín, a veces en forma de un proselitismo agresivo, aunque en la regla más a manera de sugerencia (Carrión Cachot 1948, pp. 63 65; Patterson 1971, p. 46; Lumbreras 1972; Paulsen 1974, pp. 604 605).

El fenómeno de oráculo como institución socio-religiosa parece datar de épocas muy tem- 
pranas en la historia de las religiones. Precisamente se da en un nivel cultural donde se institucionalizó la religión como tal (Gibson 1961, p. 35, cit. en Paulsen 1974). Inclusive en la etnografía moderna hay ejemplos de oráculos que como en el caso de los Ibo (Oittenberg 1958, cit. en Paulsen 1974) se han formado "sin super estructurapolítica alguna ni del tipo federación ni de estado ubicados en posiciones geográficas estrategicas donde reciben influencias del Norte, Sur, Oeste y Este por parte de adivinos, chamanes y sacerdotes, quienes emprenden a veces viajes de distancias considerables". Este punto también es de importancia para el Formativo peruano pues tenemos la ventaja de no tener que contar necesariamente con superestructuras complicadas que serían difícilmente comprobadas a base de la evidencia disponible.

Veamos de nuevo el caso de Pacopampa. Como ya queda mencionado es el sitio más grande en toda la configuración de sitios formativos del valle. En sus dimensiones destaca por ser al menos seis a siete veces más extenso que cualquier otro. Si bien tenemos plataformas y arquitectura en algunos otros, la arquitectura principal se caracteriza por ser monumental. El patrón no está muy claro debido a la falta de suficientes excavaciones, sobre todo para la fase $\mathrm{B}$, y a causa de derrumbes laterales que modificaron el aspecto general. Las estructuras son mayormente plazas hundidas con gradería, guardando la simetría conocida del sitio Chavín de Huántar. Es el único sitio donde se han hallado objetos de arte lítico como columnas, dinteles con relieves y morteros ceremoniales, un ídolo y dos felinos (otros ejemplos de arte lítico pertenecen a sitios post-formativos encima de Querocoto). Rosas y Shady (1970 a, pp. 25-29) excavaron un muro que acusa otras fases arquitectónicas relacionadas también con otros tipos cerámicos, lo que hace pensar en la posibilidad de un patrón diferente anterior al cual también pertenecerían las galerías subterráneas (los canales parecen tener afiliaciones con Pacopamapa y Chavín; op. cit., p. 17, véase figura 9). Varias galerías se encuen- tran en las diferentes plataformas y sugieren intercomunicaciones subterráneas quizás semejantes al patrón conocido de Chavín de Huántar (si existen lo tendrán que demostrar futuras investigaciones, sería posiblemente más antiguo que aquello).

Las excavaciones más extensas realizadas por Rosas y Shady no han sido publicadas en forma final aunque sí existen varios artículos preliminares (Rosas y Shady 1970 a, b, 1975). Según estos trabajos muchos elementos fuera de la cerámica denotan objetos suntuarios como espátulas de hueso con representaciones zoomorfas y antropomorfas, pedazos de roca de cristal, conchas marinas, pendientes de dientes de carnívoros (felínicos?), antracita, chaquiras de crisocola, malaguita (Fung 1975, p. 188) y vasos de piedra. Cabe mencionar que no aparecen Strobus spondylus (un fragmento de Strombus fue encontrado en una tumba de Cajamarca IV en Pandanche, lo que comprueba su existencia post-formativa).

Finalmente, hay que mencionar la cantidad de huesos de animales que aumentan en el Periodo "Chavín” de Rosas y Shady (1975, p. 24), lo que los autores atribuyen al aumento de la cacería pero que no concuerda con la agricultura avanzada. Más probable parece ser su uso como animales de sacrificio. Todos estos elementos parecen indicar su probable función como centro ceremonial.

Además muchos de estos elementos enumerados más arriba pertenecen a zonas fuera del área, lo que da la impresión de un centro receptivo. Una evidencia más sería la cerámica. Descripciones de ésta existen en dos trabajos (Rosas y Shady 1970 a, Fung 1975).

Lamentablemente los dos informes no proporcionan porcentajes, aunque el trabajo de Rosa Fung es más detallado y preciso. Fuera del hecho que la cerámica decorada alcanzaría porcentajes altos (no indicados), tenemos una situación particular que se refleja bien en el Cuadro I de Rosa Fung (1975). Si bien los ocho rasgos decorativos pertenecen a seis fases (según su 
secuencia), éstas denotan una distribución peculiar. Por un lado tenemos la cerámica llamada "líneas incisas cortantes" (Rasgo 1) y "líneas incisas superficiales" (2), que es la cerámica típica del lugar. El rasgo 1 tiene más de 41\%; el rasgo 2 más de $7 \%$. Existen 16 rasgos representados por un solo fragmento, 9 con dos fragmentos respectivamente y 4 con tres fragmentos, lo que da precisamente la mitad de todos los rasgos. Solo tres rasgos tienen porcentajes entre $4 \%$ y $8 \%$, algo como 10\% del total. La subdivisión en tantos rasgos se justifican con la descripción. Esta diversidad podría explicarse si al menos parte de esta cerámica no es del lugar. Nuestra colección de Pandanche demuestra la misma tendencia.

Hay muchos fragmentos que por varios criterios (pasta, forma y decoración y correlación espacial) son influencias foráneas. La procedencia no es muy clara en muchos casos por falta de referencias (Kaulicke 1975, s.f.b.). Pero nunca estos vestigios sugieren una influencia muy directa o aun ocupación de otras zonas. Un fenómeno semejante podría ser la llamada "Galería de las Ofrendas" (Lumbreras 1975, pp. 52-53). La diversidad de los objetos hallados incluye objetos de hueso, dientes de niños y Spondylus (op. cit., pp. 41-42).

Igualmente, Chavín parece haber recibido cerámica de otras partes como pedestales semejantes a los de Garbanzal, vasijas de Cupisnique, Kuntur Wasi, Jequetepeque y otras zonas no determinadas. Aún el mismo estilo "ofrendas" parece algo problemático pues es relativamente común en Ancón, pero fuera del centro ceremonial de Chavín de Huantar donde aparece esporádicamente. Faltan aún secuencias más refinadas para poder clasificar claramente estas evidencias, aunque parece obvio que Chavín recibió objetos suntuosos de otras regiones a veces muy distantes, lo que ocurre también en Pacompama. Burger (comunicación personal) parece haber encontrado fragmentos de Pacopampa en capas "pre-Chavín" fuera del centro ceremonial, lo que indicaría un intercambio de objetos puesto que hemos encontrado frag- mentos "ofrendas" en nuestras excavaciones en Pandanche. Otro caso es la cerámica que Rosas y Shady llaman "Modelado Cintado" y es ésta la que más claramente demuestra rasgos felínicos. Parece que está muy restringida en su distribución espacial y no la hemos encontrado en las excavaciones en Pandanche aunque si en la superficie. La muestra de Fung (1975) no hace reconocer claramente este tipo (fase D?) debido al tamaño reducido de los fragmentos, mientras Flores (1975) encontró varios especímenes en otro lugar de las ruinas de Pacopampa, fuera de la pirámide. En las colecciones de superficie de los otros sitios está ausente.

Esta cerámica, como ya queda mencionado, muestra un fuerte énfasis en las representaciones felínicas aunque claramente asociadas a elementos antropomorfos. Su aparición parece datar de fases relativamente tardías. Pero también existen algunas representaciones figurativas con la cerámica Inciso Cortante, aunque se trata de un felino que no tiene mucho parentesco con los conocidos de Chavín de Huántar. Se caracteriza por su ojo excéntrico, volutas que forman el contorno de la cabeza, mientras los colmillos no están representadas muy claramente. Otro tipo es un elemento compuesto por dos ojos redondos con una boca formada por líneas rectas (una de base y otras dos divergentes hacia arriba, en los extremos de la primera) que podrían ser serpientes o peces. En la muestra de Pandanche éstas y otros tipos modelados (principalmente ojos de "grano de café" o más elaborados y una figurina antropomorfa sin cabeza) no representan más de $1 \%$ de la muestra de cerámica decorada respectivamente y pertenecen en su gran mayoría al B II. En una publicación de Rosas y Shady (1970 a, lám. 4b) una representación en contorno con colmillos parece datar más bien al C I, tal como un fragmento muy semejante con pintura postcocción que encontró T. Pérez en la superficie del centro ceremonial (comunicación personal). Con el C I de Pandanche no se han registrado estos tipos. Las muestras de arte lítico y tallados óseos coinciden mayormente con los motivos 
mencionados aunque son más elaborados. Incluyen motivos ornitomorfos, pero su numero limitado no permite mayores conclusiones.

Estos porcentajes mínimos de representaciones felínicas tendrán que encontrar su contraparte en otras secuencias del Formativo. Como no es muy usual en muchos trabajos indicar porcentajes por motivos decorativos, una comparación directa es algo difícil. Pero parece que en muchos sitios relacionados con evidencias "Chavín", la situación no es muy diferente.

Sólo en el caso de la cerámica encontrada en la galería de las Ofrendas probablemente aparece un porcentaje muy alto de elementos figurativos entre los cuales parece predominar el felino, aunque habría que esperar el informe final para confirmar lo supuesto.

Estas observaciones se confirman por dos comunicaciones personales. Isabel Flores recientemente recuperó mucho material cerámico cerca del sitio ceremonial, o sea el "Templo" de Pacopampa, lo que aparentemente pertenece en su mayoría al B II y dentro del cual hay una cantidad apreciable de representaciones felínicas; mientras por el otro lado, Richard Burger tiene dentro de su material de Chavín (fuera del centro ceremonial), que cuantitativamente es notable, representaciones felínicas en porcentajes minúsculos (ambos por comunicación personal).

Para poder entender en algo esta discrepancia sería necesario ensayar una interpretación de este simbolismo. El material de Chavín de Huántar serviría para este fin puesto que es mejor documentado, los especímenes son más variados y numerosos, y su realismo permite reconocer los elementos como tales.

\section{La simbología Chavín}

Muchos de los elementos figurativos dominantes en el arte Chavín están presentes también en tiempos post-formativos. Así ocurre con el felino, la serpiente, las aves, el Spondylus y el Strombus, y otros que forman conjuntos de símbolos dominantes y secundarios. Turner (1973, p. 25) define el símbolo dominante como "una unificación de varios y diferentes significados". Los significata dispares se interconectan en razón de poseer en común cualidades análogas o por asociación, pueden ser en sí mismos triviales, casuales o estar ampliamente distribuidos en toda una gama de fenómenos. Esta definición podría ser útil también para nuestro propósito, el de interpretar algunos puntos de significancia en la iconografía de Chavín. Es entonces algo restringido el interpretar animales al establecer una taxonomía. En el fondo no es tan interesante saber si un felino pertenece a la especie Felis onca, Felis concolor o Felis jacobita, sino lo que importa probablemente es lo que Sawyer (discusión en R. Dolmatoff 1970, p.66) sospecha que son los dientes felínicos de cualquier animal que tenga colmillos o con otras palabras, el elemento felínico en sí. Por el otro lado, hay que remarcar que el conocimiento taxonómico es notablemente alto entre grupos a nivel de banda y en sociedades tribales. Según la definición de Turner, sin embargo, una ilustración en el sentido taxonómico no cabría dentro del término símbolo.

Hay algo más, elementos característicos en la iconografía Chavín se perpetúan hasta en tiempos de la Colonia o para ser más preciso, hasta la actualidad. Esto significa que tales elementos o símbolos no son valores exclusivos del Formativo sino que representan altos valores en los sistemas de valores andinos. Si bien los significata cambiaron en el curso del tiempo, su misma complejidad - de la que nos ocuparemos en adelante-induce a una idea fundamental, un principio. Para darnos cuenta de esta gama de significata, de la cual se componen elementos como lo felínico, las aves, serpientes y conchas marinas, hay que recurrir a varias fuentes tal como la hizo ya Tello (1923) en una monografía insuperada hasta la actualidad: las fuentes históricas, las fuentes etnográficas y las fuentes arqueológicas.

\section{El Felino}

Sin tener el propósito de agotar este tema, cabe notar que este animal está considerado generalmente como algo mucho más allá de un 
animal poderoso cuya apariencia induce miedo. Hay varios trabajos que reúnen este fenómeno (Tello 1923, Kunike 1923, Furst 1968, Reichel Dolmatoff 1970). Muchas conexiones allí no tienen ninguna referencia directa hacia la apariencia o el comportamiento del animal real. El felino aparece en la mitologías cosmogónicas, donde ejerce un papel decisivo, representa cuerpos siderales (Pléyades), está en conexión con el rayo y trata de devorar el sol y la luna; es el progenitor de los hombres, el guardián-espíritu del chamán y de los sitios ceremoniales, el "señor de las especies". Entre los incas adopta afiliaciones con los guerreros -quienes se convierten en estos animales durante la batalla- y está en conexión con los alucinógenos. El jaguar mítico o mágico se convierte en monstruo semi-antropomorfo o está provisto de alas. De ninguna manera es el animal en sí el que causa temor o devoción, es el ser mítico-mágico al que temen. Tiene importancia elemental tal como lo expresan los indios arauaks: "todo tiene jaguar" (Reichel Dolmatoff 1970 , p. 61). Es el concepto de la fertilidad masculina, una energía natural que se reconoce en cada acto creativo.

En el mundo andino, el felino además de tener vínculos con los chamanes se encuentra ligado a cuerpos celestes y se convierte en emblema de la clase dominante, haciéndose manifiesta de esta manera su importancia en el contexto social.

\section{Aves}

En la iconografía Chavín el motivo ornitomorfo aparece o como elemento secundario o como ser mitológico formando un conjunto con elementos felínicos; este último parece ser muy común. Por ello, el ave definitivamente tuvo una importancia mayor, lo que se perpetúa en la iconografía andina post-formativa. También este símbolo tiene más implicancias de las que se induciría del propio animal. Aparece como progenitor de ayllus, como insignias de la clase dominante, es el espíritu guardián del chamán muy fuertemente ligado con la inhalación y los efectos de los alucinógenos, aparece en los inaugurios, sus plumas sirven para el sacrificio, guerreros se convierten en cóndores, gavilanes, etc, durante las batallas. Algunas están relacionadas con la producción del guano, aparece en los oráculos y sus plumas se las echaba delante del Inca para que no pisase el suelo (Santillana, Molina, Arriaga, Poma de Ayala, Furst, Tello).

\section{La Serpiente}

Igualmente la serpiente está muy frecuente en las representaciones aunque más como elemento secundario. Su implicancia en la mitología andina es de destacada relevancia. También ella es insignia de jefes y guerreros, está relacionada con lagos y el agua en general, está representada en cuerpos siderales, en trueno y relámpago, aparece en monstruos felínicos, es espíritu guardián del chamán y desempeña un papel importante en ritos pluviómagos (Cobo, Albornoz, Retanzos, Ávila, Pachacuti, Girard, Harner, Urbano). Parece que su relación con el elemento agua es de suma importancia sea agua terrestre o agua que cae del cielo. Se proyecta por ello hacia la fertilidad agrícola.

\section{Conchas marinas}

Spondylus y Strombus no son tan frecuentes en las representaciones pero están relacionados con los seres míticos más importantes. Su uso ritual parece haberse originado desde muy temprano (mucho antes de la aparición de Chavín) y subsiste hasta la actualidad. También su significancia es múltiple. Es ofrenda para los dioses: en forma de polvo fue echado delante de los reyes del norte para que no pisasen el suelo (Cabello de Balboa), es comida de los dioses (Ávila), tiene relación con la fertilidad agrícola (Medina) y el Strombus sirve de trompeta en ocasiones de importancia ritual (hasta la actualidad). Las conchas marinas hasta el presente "sirven de copa, en la que a los dioses se sirve el vino y el aguardiente que se les ofrece" (Casaverde). Mircea Eliade (1974, p. 137) interpreta el simbolismo de las conchas marinas como simbolismo sexual por su semejanza con los órganos 
sexuales de la mujer y, por lo tanto, es símbolo de fecundidad, un aspecto que ciertamente es aplicable también para la región andina.

Vemos en esta relación de significata una cierta homogeneidad, la identificación de algunos animales con elementos naturales que se reflejan en la esfera social (de grupos dominantes) y la producción en forma directa o indirecta (mediante la intervención del chamán). Es obvio que estos dos puntos presentan estrechos vínculos. Cabe destacar que esta trinidad felino-ave-serpiente está en pleno vigor entre las tribus selváticas horticultoras. Este hecho es importante si vemos que en el desarrollo del arte lítico de Chavín de Huántar la fuerza y la pureza en las representaciones de estos elementos se está perdiendo paulatinamente, haciéndose casi irreconocible en las últimas fases; mientras en el post-formativo siguen existiendo aunque en forma menos perceptible. La razón puede buscarse en la situación de transición que mantiene aún ideales de cazadores, que-como dice Macera- frecuentemente muestran tendencias de convertirse en emblemas de la clase dominante.

No quiero entrar en una interpretación detallada de la iconografía para comprobar lo dicho más arriba, sino quisiera concentrarme en un ejemplo destacado, el llamado "Obelisco Tello". Después de una interpretación minuciosa hecha por el mismo Tello, el objeto está mencionado con frecuencia pero sin mayores intentos de interpretaciones alternativas. Rowe (1962, 1973) identifica la imagen como caimán, pero encuentra ciertas dificultades en mantener esta identificación. Los caimanes son representados con cola de pescado, pero este detalle mítico puede haber sido mero error de los escultores, pues éstos han podido representar animales que no conocieron personalmente dado el hecho que los caimanes viven a una altura mucho más baja. Hay una cierta incongruencia en este argumento, puesto que un "Kjenning" (metáfora en la poesía nórdica para designar atributos secundarios) no lo sería si el elemento no requiere de interpretación alguna, como en el ejemplo de esta "cola de pescado", y es por ello algo precipitado hablar de "errores de los escultores". En una discusión, Sawyer pone en duda la interpretación como caimán y sugiere un felino muy elaborado: la cola incluso podría ser la de un halcón o águila y las manos las de seres humanos. Tello interpretó la estela como representación del felino Wari, dios de la agricultura asociado a la serpiente, cóndor y pez, símbolos del Rayo, Sol y Luna respectivamente. Son dos aspectos de la misma divinidad cuyo poder o atributo principal es otorgar a los humanos los frutos alimenticios. Bajo la acción de otros poderes de la naturaleza, simbolizados por un cóndor, un pez y un monstruo serpentiforme, esta divinidad prodiga frutos y semillas. Pero cuando el animal destroza o devora a los animales secundarios que simbolizan dichos poderes, entonces las semillas germinan, crecen y florecen. El primer aspecto de esta divinidad puede significar el agente que origina el periodo seco o caluroso, cuando desaparece la florescencia y quedan solo las semillas; el segundo, el periodo oscuro y lluvioso del invierno en que dichas semillas germinan y crecen... seguramente un ciclo mitológico relacionado con los poderes de la naturaleza que influyen directamente en la conservación o destrucción de los valores socioeconómicos de la humanidad. Esta interpretación es sorprendentemente moderna, como lo subrayó ya Lathrap, quien incluso ve allí elementos estructuralistas. En otra ocasión, el propio Lathrap se ocupa del mismo tema (1973) y trata de identificar algunas de estas plantas, que Tello ya había reconocido como plantas alimenticias, y llega a identificar la yuca, que sale del pene de una de las representaciones, el maní y el ají.

Veamos la representación algo más en detalle. Para la descripción se usará la clave y la reproducción de Rowe (1973). Es obvio que se trata de dos representaciones casi idénticas. Las diferencias se concentran en tres grupos A1, A2, A10 con sus respectivas contrapartes B1, B2, B10 alrededor de la cabeza. A21, 23, 24 con B21, 22, 23, 24 se encuentran entre las extremidades delanteras y traseras. La representación B parece 
algo más "completa", teniendo dos atributos más que A (B3 y P22). Las demás partes son o idénticas o muestran ligeras modificaciones. Así, 14, 18,27 y 36 mayormente se refieren a los colmillos, los cuales tienen una línea divisoria en $\mathrm{B}$ y hay diferencias en las formas, como en 18, que tiene además un "lagrimal" debajo del ojo, y 36, que también está invertido.

La parte más dominante es la cabeza (A/B6), la cual mide casi un cuarto del largo de la representación total. Es probablemente el elemento más decisivo que indujo a su identificación como caimán (cuatro colmillos). Es importante anotar que esta cabeza es muy difundida como motivo decorativo en la cerámica llamada "ofrendas". Además aparece desde la fase 1 hasta la fase 3 de la secuencia de Scheele para Ancón y Lurín, y el Garagay en los motivos 2, 5, 6 de los murales recientemente descubiertos. En la regla se trata de cabezas aisladas. Se hace más difícil su identificación como caimanes en estas representaciones que en el "Obelisco Tello". La única diferenciación puede estar en la multiplicación de los colmillos; los demás rasgos son felínicos. Esta multiplicación, sin embargo, es común en la iconografía Chavín, sobre todo en la cadena de colmillos y dientes que forman la columna vertebral, lo que posiblemente no sería nada más que un aumento de la fuerza felínica que transcurre por todo el cuerpo para emanar hacia fuera a través de los órganos sexuales. También las extremidades, salvo por su posición, hacen difícil su correlación con un reptil. En la regla es posible identificar una pata de ave de una garra felínica, y aquella del pie o la mano del ser humano. Según esa convencionalización las manos serían humanas y muy semejantes a las del Lanzón. Con el Lanzón comparte además los apéndices cefálicos de serpientes y aretes pendientes (A/B4 y 8), y también lleva brazaletes. En el caso del Obelisco Tello son serpientes enrolladas (A/B12 y 33). Finalmente, la "cola de pescado" consiste de cabezas felínicas elaboradas de las cuales salen objetos alargados en número de cuatro. Estos más bien dan la apariencia de ser plumas de cola de ave. Como se verá más adelante hay algunas evidencias que se relacionan con la sexualidad. La posición que estas representaciones demuestran se explicaría más fácilmente si se interpreta el total como una especie de acto sexual.

Lo que se podría extraer de lo que se acaba de mencionar es que no se trata ni de un caimán, ni de un felino sino, como es común en la iconografía Chavín, es un ser que combina varios elementos aunque hay que resaltar que el componente felínico es destacado.

Cabe ahora tratar aquellos elementos que difieren entre las dos representaciones. El primer grupo delante de las cabezas consiste, en el caso de A, de dos elementos (A1 y A2), de los cuales A2 ha sido identificado como Spondylus (Rowe 1973 , p. 268) que parece también otra representación (del Dios Sonriente, Rowe 1973, fig.21), la cual también es semiantropomorfa, con cabellera de serpientes, brazaletes y aretes pendientes. Parece entonces que las tres imágenes tienen algo en común: posiblemente se trata de varias facetas del mismo personaje. Lo que es interesante es la posición del objeto A2 que parece estar a punto de introducirse a la boca de la imagen, tal como A1, mientras que en el caso de B los elementos más bien parecen salir de la boca. Quizá no sea casualidad el hecho de que una divinidad en Ávila devorara mullu. (Ávila 1966, cap. 23, Macahuisa está relacionado con el rayo, su actitud de comer mullu está anotado claramente como un hábito pre-incaico). Se notará también que en la misma representación A el Strombus (A21) está orientado hacia el órgano sexual masculino, mientras el Spondylus, como vimos más arriba, tiene fuertes conexiones femeninas. De la boca de B salen tres de los animales, de los cuales el pez está más cerca de la boca.

Si bien las dos representaciones se diferencian por lo que les rodea parece que esto es solo el resultado de lo que está ocurriendo en el interior, el cual está dominado por una cadena de dientes y colmillos. Ella termina en una cabeza felínica (A/B 25), la cual está sujetada por un personaje que está compuesto por los elementos 26, 27, 28, 
mientras en su comienzo está otro (A/B15). Éste es casi completamente antropomorfo, con sus manos humanas muy elaboradas, la boca torcida hacia abajo, sin dientes, con un tocado especial que sobrepasa la cadena de dientes, y sus ojos están torcidos hacia arriba. El ojo no es muy típico, se asemeja mucho al elemento A21 (el Strombus) y encima de la nariz lleva el apéndice típico para los elementos felínicos. Este último no aparece en la cara del otro personaje que también tiene un aspecto muy antropomorfo, en realidad es sólo la boca felínica la que hace dudar en su identificación de ser humano, tampoco demuestra la obesidad de 15. Está volteado hacia los órganos sexuales y agarra con un lazo lo que podría ser la columna vertebral.

Esa posición y su actitud parecen estar ligadas al proceso de la procreación, y efectivamente salen objetos de los que nos ocuparemos más adelante. También destaca este personaje por su corona muy elaborada. Eliade analiza este simbolismo que al parecer está muy difundido. En muchos idiomas "ligar" y "embrujar" se expresan por la misma palabra. Da la impresión que este personaje controla la fertilidad con medios mágicos, por lo cual es posible que sea nada menos que una especie de chamán. En Harner (1972 p. 24), un chamán en trance tiene algo parecido a una corona en la cabeza que es sólo visible por los que han inhalado los alucinógenos, así como por el mismo chamán también. Puede que esta comparación no sea tan osada en vista de que la apariencia humana del personaje es evidente, como ya queda mencionado.

En la literatura antropológica las referencias acerca de prácticas chamanísticas y experiencias alucinógenas no escasean. El estrecho vínculo que tiene el chamán con el jaguar le permite convertirse en aquello que para él es una realidad, puesto que es una experiencia visual bajo el efecto de drogas. Un famoso cántaro en la colección de Larco ilustra la mitad de una cara felínica y la mitad de una cara humana indicando precisa- mente este proceso de transformación. En toda la región andina se conocen prácticas chamanísticas desde el comienzo de la intervención europea en el siglo XVI hasta nuestros días. Los agustinos (1921, pp. 15-19) dan una descripción muy detallada de la iniciación de chamanes entre los cuales cuentan también a los sacerdotes (cuyo espíritu guardián es un águila) y conectan sus oficios con el oráculo. En estas fiestas relacionadas con el oráculo van "coronas de plumas redondas", lo que quizá se puede relacionar con el elemento 28. Semejantes adornos mencionan también Arriaga (1968, p. 222) y Albornoz (1967, p. 22). Willey y Corbett (1952, p. 149) y Uhle encontraron restos de coronas de plumas en Supe que datan del Formativo (las plumas venían de la selva). Arriaga habla de transformaciones en lechuzas y la conexión con felinos. Hasta ahora existe el chamanismo con toda su complejidad y relacionado con el rayo (Casaverde 1970, p. 212).

Mientras que muchos de los elementos de los cuales se compone la "Gran Imagen" son reconocibles, hay algunos que no lo son, sobre todo el B24 y el A10. El B24 tiene una posición muy importante que corresponde al órgano sexual de A. Cabe notar que este atributo también tiene una distribución más difundida en la cerámica "ofrendas", algunas piezas de cerámica Cupisnique, otros relieves y el célebre mortero de Pennsylvania. Parece probable entonces que no se trata de una planta o semilla cualquiera sino que conlleva un significado importante relacionado mayormente con el felino. Reichel Dolmatoff (1972, p. 62) menciona que en algunas tribus colombianas la denominación "semilla del jaguar" se atribuye a sustancias alucinógenas. Los llamados morteros ceremoniales, como el de Pennsylvania, también podrían haber tenido el uso de aquellos objetos que Albornoz llama "vilcanas", objetos en forma de animales con un hoyo en el lomo donde se pulverizaban plantas narcóticas, en este caso la wilka ${ }^{1}$. Me parece nece-

\footnotetext{
${ }^{1}$ Los morteros encontrados en Pacopampa por Larco son diminutos, cualidad que excluye muchas otras posibles funciones.
} 
sario insistir algo en este punto. Esta planta "wilka”, según Albornoz, proviene de los Andes calientes, se cura y purga con la misma y se entierra la planta en las tumbas.

Wassén (1972 a,b) identifica esta planta como Anadenanthera colubrina; Yacovleff y Herrera (1935, p. 43) como Piptadenia colubrina. Estos últimos mencionan la leyenda conservada por Santa Cruz Pachacuti, quien habla acerca del entierro de un tal Vilca-quire debajo de un árbol. Como fue un capitán incaico muerto por los Chanka, se podría quizá relacionarlo con el oráculo de Andahuaylas que primero se sitúa en territorio chanka y segundo es un oráculo que funciona en un árbol con tronco vacío. Esto también comprobaría el uso de la planta en este oráculo. Soukop (1970, p. 265) dice de Piptadenia que la "semilla pulverizada y tomada en forma de rapé es muy narcótica”. Otra semilla muy usada era el "espingo", dada como ofrenda a las huacas y también se relaciona con las conopas (Arriaga 1968, p. 209,211).

Este espingo se comercializó y los de Jaén de Bracamoros pagaban con ellas su tributo (una perspectiva muy especulativa pero sugestiva: el intercambio con plantas alucinógenas que subrayarían las necesidades de intercambios con la montaña, en este caso de una zona muy cercana a la de Pacopampa). Villagómez (1919, pp.165166) la describe como semejante a almendras muy relacionada con las conopas. Cobo $(1964, \mathrm{t}$. I, p. 165) también la menciona y dice en otro lugar, hablando de oráculos, que "no pocas se le aparecía visiblemente (el demonio) en varias y espantosas figuras, como de serpientes y de otros animales fieros, y hablaba con ellos", y más arriba "usaban (los hechiceros) de ciertas unturas y se emborracharon hasta perder el sentido, y después, a cabo de un día, decía lo que les preguntaban...la ceremonia principal era emborracharse, echando en la chicha el zumo de una hierba llamada vilca". El espingo reciben los callahuayas (chamanes bolivianos) de Cajamarca en la actualidad (Wassen 1972, p. 41 ), lo que indica intercambios a distancia sorprendente.
Es algo difícil comprobar la existencia del uso de alucinógenos en el Formativo aunque parece que ya se practicó desde muy temprano (Huaca Prieta 1200 a.C., cit. en Furst 1968, p.161). Hay algunos huesos tubulares decorados con motivos felínicos en Chavín (Tello 1960, p. 177) que podrían sugerir el mismo uso. Una interpretación, como otra prueba, podría buscarse en las cabezas clavas, algunas de las cuales poseen anillos que salen de las fosas nasales prolongándose hasta debajo del mentón (Tello 1960, fig. 123-124, entre las cabezas no publicadas hay varios ejemplos más). Se sabe que entre los Waika o Yanomamo se suele ingerir la droga mediante un tubo que contiene el alucinógeno. Una persona sopla esta sustancia a la nariz de la otra. Al momento de dar efecto las fosas nasales comienzan a segregar un moco verde causado por la irritación. Este se prolonga estando la persona ya en trance, o en otras palabras, cuando ya había pasado por una transformación. Este fenómeno podría tener algo que ver con los anillos de las cabezas clavas y explicar hasta cierto punto la ilustración de mezclas antropozoomorfas en una misma pieza.

Otro elemento que es difícil de interpretar es el atributo A10 que también se encuentra en la Galería de las Vigas Ornamentales asociado a un pez con atributos felínicos, lo que podría relacionarse con el agua como esencia de la fertilidad agrícola. Es posible, también, que se trate de nada más que una cruz más elaborada cuya distribución en el Formativo es difundida (aparece ya en Wairajirca), y se conecta con mucha frecuencia con el felino (Palomino 1968), lo que demuestra vínculos estrechos con la agricultura (abundancia y escasez de agua).

Parece entonces que muchos de los elemento que componen la "Gran Imagen" se vinculan con la fertilidad en varios aspectos, interpretando la fecundidad con motivos mágico-religiosos en un contexto que capta reflejos de una religión en estados tempranos. Ni siquiera está muy claro si se trata realmente de una divinidad, más bien se asemeja a un concepto que en antropología se 
suele denominar "señor de las especies". El interés principal y el motivo de estas representaciones son el fomento y la aseguración de la buena voluntad de las fuerzas que dominan la agricultura en forma cíclica.

Tello (1923) correlaciona el jaguar además con las pléyades citando a varios cronistas. En los agustinos (1918, p. 41), éstas tienen claras connotaciones con productos agrícolas (ají). En Avila (1968, p. 15), pumas actúan en una fiesta dedicada a una diosa importante del panteón de los Yauyos con fuertes implicancias hacia la fertilidad y sexualidad. La fiesta coincide con la aparición de las pléyades en junio, que en todos los calendarios figura como de las más principales. Tello además sugiere una cierta polaridad entre las dos representaciones de la "Gran Imagen", verano-otoño (A), invierno-primavera (B), lo que es una interpretación muy sugestiva. Cabe mencionar una nota de Pachacuti, quien describe el Chuquichinchay (Pléyades), como "animal muy pintado, de todos los colores, dicen que era apo de los Otorongos, en cuya guarda da a los hermafroditas, yndios de dos naturas". Aparentemente hubo tal mito relacionado con las Pléyades cuyo contenido no se ha conservado a nuestros días.

Cabe destacar, finalmente, que es el sentido de la fertilidad el que está detrás de muchos símbolos de la iconografía Chavín. La fuerza felínica es una fuerza elemental que requiere del control, pues lleva inmanentemente las posibilidades de efectos positivos (abundancia de productos comestibles) y negativos (sequía, falta de alimentos, hambruna). El que está encargado de este control es el especialista del culto: sea chamán, sea una forma más evolucionada. Se requiere del culto para garantizar el éxito de las cosechas y esta garantía es más convincente si es el "responsable directo" el que habla. Y solo lo hace en una forma: en el oráculo.

\section{Conclusiones}

Finalmente habrá que anotar algo acerca de los cambios ocurridos en tiempos postformativos para esclarecer más lo arriba mencio- nado para la zona de Pacopampa y para entrar después en la discusión final con un intento de explicación para este sistema. Los sitios del Intermedio Temprano cubren un área mucho mas extensa que la del Formativo, estableciendo grandes centros en los cerros (Jalca) que rodean el valle. Estos demuestran claros rasgos de una evolución urbanística al formar grandes núcleos mucho mayores que el propio sitio de Pacopampa. Inclusive la Playa está provista de asentamientos que parecen llegar a su auge en el Horizonte Medio Tardío, algo que no parece ser tanto una ruptura con el Formativo sino más bien como resultante del mismo.

La ubicación de los grandes centros en las alturas parece también corresponder a consideraciones estratégicas, tanto como una extensión de la zona de cultivo que ya no se restringe al mismo valle (Kaulicke 1975a, sección Medio Ambiente, lámina XXII). Algunos de los sitios formativos mantenían u obtuvieron carácter sagrado, lo que se nota por entierros intrusivos (en Pandanche se encontró una tumba de Cajamarca IV, acomodada forzadamente entre construcciones del Formativo Tardío, Kaulicke 1975, pp.36-38). Hay indicios de muchos entierros semejantes en el mismo sitio.

Para entender el mecanismo del intercambio en el Formativo y dentro de sistemas cerrados, hay que recordar algunos puntos en relación a Pacopampa.

1. El intercambio con zonas ecológicamente muy diferentes está dado de una manera relativamente fácil tanto dentro del valle como hacia la costa y la selva. Distancias por debajo de los cien kilómetros no representan obstáculos insuperables por medio de intercambio directo o indirecto.

No hay la necesidad de explicar exclusivamente toda la estructura por peregrinaciones atraídas por centros ceremoniales, también porque tal fenómeno suele ser el resultado de ciertas circunstancias.

2. La pequeña zona del valle de Pacopampa forma un nicho ecológico que permite un rendi- 
miento relativamente alto de una agricultura a bajo nivel tecnológico y un potencial de zonas de cultivo adicionales y ecológicamente diferentes mediante técnicas más avanzadas.

3. La cercanía de la costa es significativa en cuanto a varios factores. El acceso a productos marinos también de carácter suntuario (conchas marinas, etc.), mientras que Pacopampa ofrecía minerales apreciados en el Formativo (oro, piedras preciosas o semi preciosas mas productos de piedras como vasos, etc. $)^{2}$.

4. El contacto con la selva se hace necesario por otros productos como quizá también oro (fluvial, lo que se encuentra también cerca del mismo sitio de Pacopampa), plumas de aves, etc. Otra vez se establecerá como intermediario con la costa y quizá también los alucinógenos. Es interesante el hecho que también en Bagua, a 100 $\mathrm{km}$ al NE de Pacopampa, se haya encontrado cerámica muy semejante (Inciso Cortante con pintura post-cocciónen áreas y un inventario de formas muy semejantes a las de Pacopampa; incluso el patrón de asentamiento denota similitudes aunque en un nivel inferior, Shady 1971). En este caso no es posible esclarecer preferencias temporales o tipos de contactos (iinfluencias de Pacopampa hacia Bagua, o al revés o en ambas direcciones?).

5. La existencia de huesos de camélidos y su probable uso para sacrificios, más otras necesidades difícilmente detectables, hacen probable el contacto con otras zonas de la sierra, lo que finalmente hace de Pacopampa un punto muy importante dentro de la red de intercomunicaciones.

6. Las posibilidades de una extensión mayor que debería ser el resultado de esta ubicación ventajosa sólo son limitadas. Hemos visto que al menos la zona nuclear en el Formativo no excedía los $24 \mathrm{~km}^{2}$.

Con estos puntos tendríamos un vehículo útil para poder entender algo más del mecanismo interno y la argumentación étnica y de transformación de aquellas circunstancias.

a. La concentración de los sitios y su interrelación hace pensar en una unidad étnica que se basa en los principios del parentesco. Si éste sería exógeno tendríamos también una explicación de la existencia de algunos productos ajenos, aunque resulta ser una reflexión especulativa y no explicaría el total de los fenómenos que demuestran influencias del exterior y mucho menos su función. Una idea semejante en ReichelDolmatoff (1972, pp. 56-57) está relacionada a conceptos felínicos en Colombia. Esto significa que la reciprocidad dentro del sistema es limitada, pero precisamente este hecho hace necesaria la concentración visible en un lugar que permita un aumento de prestigio para todo el sistema.

b. Este lugar de acumulación necesariamente se relaciona con el centro mítico-mágico de la étnia, lo que se llama en tiempos prehispánicos tardíos, las pacarinas o pacariscas. Tal lugar probablemente ha sido Pacopampa, quizá por su potencialidad hidrológica. Con la extensión de las redes de intercomunicación con otras zonas, éste se convierte además en "centro del mundo".

c. Las personas más indicadas para el control de la agricultura son los chamanes, quienes como especialistas religiosos desde el comienzo están en estrechos vínculos con los centros de importancia mágico-religiosa. Esta cualidad se transfiere a la nueva función múltiple del centro sagrado, la que tiene que explicarse mediante el mismo vocabulario mítico-mágico.Una posibilidad casi consecuente sería el oráculo, tal como hemos visto más arriba.

Los chamanes cambian sus status de la misma manera como cambia el status del sitio, el que se infla en un ritmo más rápido que los sitios colindantes, puesto que los productos básicos se distribuyen en forma más fluida, pero ambos están controlados directamente por el centro ceremonial.

2 El contacto con zonas posiblemente periféricas de influencia Cupisnique podría servir de enriquecimiento notable del aparato ceremonial. Una apreciación más concreta es difícil por falta de conocimiento de aquella zona cultural y desu extensión. 
d. No es imposible que haya existido un tipo de "multiplicación" semejante a aquello de Pachacamac, fenómeno que habrá que colocar en el Formativo Tardío al final de este desarrollo. Si esto último es verídico, tal sistema socioeconómico conlleva consecuencias que hacen de este mecanismo un aparato irrentable, hecho que tampoco se resuelve por una "multiplicación". La especialización necesaria y la complejidad del aparato de culto se contraponen, a la larga, a los intereses de la étnia primero, por el crecimiento y segundo, por la atracción que representa para otras etnías de estructura diferente y de recursos económicos más bajos.

e. Esto significa que hay que considerar la posibilidad de un final catastrófico para el Formativo, una solución preferida por algunos arqueólogos. Pero por el otro lado, también existe la posibilidad de simples desplazamientos y adaptaciones diferentes que resultan en nuevos patrones que reflejan nuevas necesidades. En Pacopampa parece que es más lo segundo, puesto que hay signos de desintegración y debilitamiento ya en la fase C II antes que una nueva tradición postule en un nuevo patrón sociocultural. Pero como queda mencionado, ésta más parece ser una continuación que una ruptura.

Si bien muchas de las hipótesis o especulaciones expresadas en este artículo pretenden tener un carácter explicativo, éste se basa en datos muy poco firmes como reflejo del conocimiento actual muy fragmentario del Formativo. A pesar de este hecho, posiblemente algunas de estas ideas podrían servir de estímulo para trabajos futuros muy necesarios, al menos en la misma zona de Pacopampa.

\section{BIBLIOGRAFIA}

ALBORNOZ, Cristóbal de

1967 "Un inédito de Cristóbal de Albornoz. La instrucción para descubrir las Guacas del Pirú y sus camayos y haciendas". (ed. P. Duviols). Journal de la Société des Americanistes. LVI 1. París.

ARRIAGA, Fray Pablo José

1968 Extirpación de la idolatrías del Perú. Biblioteca de Autores Españoles. Tt CCIX, p. 183-277. Madrid.

ÁVILA, Francisco de

1966 Dioses y Hombres de Huarochirí. Instituto de Estudios Peruanos, Lima.

BENNETT, Wendell C.

1946 "Excavations in the Cuenca Región, Ecuador". Yale University Publications in Anthropology, $\mathrm{N}^{\circ} 35$. Yale University,New Haver.

BENSON, Elizabeth (ed)

1972 The cult of the feline. A conference in PreColumbian Iconography oct. $1^{\text {st }}$ and nov. $1^{\text {st }}$, 1970, Dumbarton Oaks Research Library and Collections. Trustees for Harvard University, Washington D.C.

BETANZOS, Juan de

1968 Suma y narración de los incas. Biblioteca de Autores Españoles, t. CCIX, pp.1-56, Madrid.

CABELLO DE BALBOA, Miguel

1951 Miscelánea antártica. Una Historia del Perú Antiguo. UNMSM. Facultad de Letras. Instituto de Etnología, Lima.

CARRION CACHOT, Rebeca

1948 "La Cultura Chavín. Dos nuevas colonias Kuntur Wasi y Ancón". Revista del Museo Nacional. vol. 2, Nº 1, pp. 88-172. Lima.

CASAVERDE ROJAS, Juvenal

1970 "El mundo sobrenatural en una comunidad". Allpanchis Phuturinga. Órgano del IPA, vol. II, pp. 121-243. Cuzco.

CIEZA DE LEÓN, Pedro

1947 La Crónica del Perú. Primera Parte. Biblioteca de Autores Españoles, t. XXVI, pp. 345- 458. Madrid.

COBO, Bernabé

1964 Obras del P. Bernabé Cobo. Biblioteca de Autores Españoles. T.XCI, XCII, Madrid.

COLLIER, Donald y John MURRA

1943 Survey and Excavation in Soutjern Ecuador. Anthropological Series vol. 35. Field Museum of Natural History, Chicago.

CHAGNON, Napoleón A.

1968 Yanomamo. The Fierce People. Holt, Pinebart \& Winston, Case Studies in Cultural Anthropology. Nueva York.

ELIADE, Mircea.

1974 Imágenes y Simbolos. 2ed. Taurus. Madrid (Trad. de Images et Symboles. París 1955).

FURST, Peter T.

1968 The Olmec Were-Jaguar Motif in the Light of Ethnographic Reality. En Dumbarton Oakd Conference on the Olmec, Washington D.C. pp. 143-178. 
FLORES F. Isabel

1975 Excavaciones en el Mirador Pacopampa. Seminario de Historia Rural Andina. Universidad Nacional Mayor de San Marcos. Lima.

FUNG, Rosa

1975 Excavaciones en Pacopampa. Cajamarca, Revista del Museo Nacional, t. XLI. pp. 129207. Lima.

GIRARD, Rafael

1958 Indios Selváticos de la Amazonía Peruana. Libro Mex. Ed. México.

HARNER, Michael

1972 The Jivaro, People of the Sacred Waterfalls. Doubleday/National History Press. New York.

HUAMAN POMA DE AYALA, Felipe

1936 Nueva crónica y buen gobierno. Institut d Ethnologie, París.

JIMÉNEZ BORJA, Arturo y BUENO, Alberto

1970 "Breves notas acerca de Pachacamac". Arqueología y sociedad $N^{o} 4$, Museo de Arqueología y Etnología de la Universidad Nacional Mayor de San Marcos, pp. 13-25. Lima.

KAULICKE, Peter

1975a Pandanche, Un caso del Formativo en los Andes de Cajamarca. Seminario de Historia Rural Andina. Universidad Nacional Mayor de San Marcos. Lima.

1975b Reflexiones acerca de la arqueología de la Sierra de Lima.

S/f El Centro Formativo de Pacopampa. Una Revisión (A publicarse en Actas del Seminario de Arqueología de la Comisión Fullbright).

KUNIKE, Hugo

1923 "El Jaguar y la Luna en la Mitología de la Altiplanicie Andina”. Inca Vol.1, No 3, Museo de Arqueología de la Universidad Nacional Mayor de San Marcos, pp. 561-578, Lima.

LARCO HOYLE, Rafael

1941 Los Cupisniques. Casa Editorial "La crónica y variedades". Lima.

LATHRAP, Donald W.

1972 Vease Benson.

LATHRAP, Donald W.

1973 Gifts of The Caiman. Some Thoughts on the Subsistence Pasis of Chavin. Variations in anthropology (ed. Lathrap y Douglas). Illinois Archaeological Survey, pp, 91-106, Urbana.

LUMBRERAS, Guillermo

1970 Los templos de Chavín. Guía para el visitante.
Museo de Arqueología y Etnología de la Universidad Nacional Mayor de San Marcos. Lima.

1972 "Los estudios sobre Chavín”. Revista del Museo Nacional. T. XXXVIII, pp. 79-92, Lima.

1975 Informes de Labores del Proyecto Chavín. Arqueológicas $N^{\circ} 15$, pp. 6-35, Lima.

MEDINA, Felipe de

1650 Relación del Licenciado Felipe de Medina, Visitador General de las idolatrías del Arzobispo de Lima. Hecha el 19 de febrero de 1650 en el pueblo de Huacho. Col. de libros y doc. Ref. a la Historia del Perú. T. III. $2^{\text {a }}$ serie. Lima.

MEDINA VALDERRAMA, Alejandro

1962 Monografía de Chota 1961. Lima.

MOLINA, Cristóbal de (el cusqueño)

1962 Fabulas y ritos de los Incas. Colección de libros y documentos ref. a la historia del Perú. T. J. Lima.

MYERS, Thomas P.

1976 "Formative Period Occupations in the Highlands of Northern Ecuador". American Antiquity, vol. 41. №3, pp. 353-360. Menasha.

PALOMINO FLORES, Salvador

1968 "La Cruz en los Andes", Amaru, Universidad Nacional de Ingeniería № 8, pp. 63-66. Lima.

PATTERSON, Thomas C.

1968 Chavin an Interpretation of its Spread and Influence. Dumbarton Oaks Conference on Chavín, oct. 26 th and 27 th. pp 29-44, Washington D.C.

PAULSEN, Allison C.

1974 The Thorny Oyster and the Voice of God Spondylus and Strombus in Andean Prehistory. American Antiquity, vol. 39, № 4, Part 1, oct., pp. 597-607, Menasha.

PIZARRO, Hernando

1921 A los señores Oydores de la Audiencia Real de su Majestad. Carta del 23 de noviembre de 1533. Col. De Libros y Doc. Ref. a la Historia del Perú.t. III. $2^{\circ}$ serie. Lima.

RAVINES, Roger

1975 Garagay, un viejo templo en los andes. Textual 10. Revista del Instituto Nacional de Cultura, pp. 1-12 Lima.

1975 "Garagay, sitio Ceremonial Temprano en el Valle de Lima”. Revista del Museo Nacional T. XLI, pp. 253-275. Lima.

REICHEL-DOLMATOFF, Gerardo

1972 The Feline Motif in prehistoric San Agustín Sculpture. The Cult of the Feline a Conference in Pre-Columbian Iconography, pp. 51-68, Washington D.C. 
1918 Relación de la Religión y Ritos del Perú hecha por los primeros religiosos agustinos que allí pasaron para la conversión de naturales. Col. De libros y doc. ref. a la historia del Perú. T. XI. $1^{\mathrm{O}}$ serie, Lima. (1650?

ROSAS, Hermilio y Ruth SHADY

1970 a Pacopampa, un Centro formativo en la Sierra Nor-Peruana. Seminario de Historia Rural Andina. Universidad Nacional de San Marcos. Lima.

1970b Pacopampa. Un complejo Temprano del Período formativo peruano. Arqueología y Sociedad, № 3, pp. 1-16. Lima.

1975 "Sobre el período Formativo en la Sierra del Extremo Norte del Perú”. Arqueológicas 15, pp. 6-35. Instituto Nacional de Cultura, Lima.

ROSTWORONSKI DE DIEZ CANSECO, María.

1972 "Breve Ensayo sobre el Señorío de Ychma o Ychima". Boletín del Seminario de Arqueología. Instituto Riva-Agüero PUCP $\mathrm{N}^{\circ} 13$, pp. 37-51.Lima.

1973 "Urpayhuachac y el Símbolo del Mar". Boletín del Seminario de Arqueología Instituto RivaAgüero-PUC, № 14, pp. 13-22. Lima.

1975 "Pescadores, artesanos y mercaderes costeños en el Perú prehispánico". Revista del Museo Nacional T. XLI, pp. 311-349. Lima.

ROWE, John H.

1962 Chavin Art: An inquiry into its Form and Meaning. The Museum of Primitive Art. New York.

1973 "El Arte de Chavin: El estudio de su forma y su significado". Historia y cultura, № 6, pp. 248-276. Lima.

SALINOW, Michael J.

1974 La Peregrinación Andina. Allpanchis Phuturinqa 7, pp. 101-142. Cuzco.

SANTA CRUZ PACHACUTI, Don Joan de

1968 Relación de Antigüedades deste Reyno del Perú (1613). Biblioteca de Autores Españoles. T. CCIX, pp. 279-319. Madrid.

SANTILLÁN, Hernando de

1968 Relación del origen, descendencia, política y gobierno de los Incas (1563). Biblioteca de Autores españoles. T. CCIX, pp. 97-149. Madrid.

SANTILLANA, Julián I.

1975 Prospección Arqueológica en Pacopampa. Seminario de Historia Rural Andina. Universidad Nacional Mayor de San Marcos. Lima.

SAWYER, Alan R.

1972 Véase Benson 1972.
SCHEELE, Harry G.

1970 "The Chavin Ocupation of the Central Coast of Peru". Tesis doctoral inédita. Harvard university. Cambridge, Mass.

SHADY SOLIS, Ruth.

1971 "Bagua, una secuencia del Periodo Formativo en la Cuenca Inferior del Utcubamba". Tesis de Bachiller. Programa de Antropología y Arqueología, Universidad Nacional Mayor de San Marcos. Lima.

OUJUO, Jaroslaw SDF

1970 Vocabulario de los nombres vulgares de la Flora Peruana. Colegio Salesiano. Lima.

TELLO, Julio C.

1923 "Wira-Kocha". Reimpreso de la Revista Inca, vol. 1 y 3 , Lima.

1961 Chavín. Cultura Matriz de la Civilización Andina. Universidad Nacional Mayor de San Marcos, Lima.

TURNER, Víctor W.

1973 Simbolismo y Ritual. Serie Antropología de la PUCP. 3. Lima (Trad. De "Análisis of Ndembu Simbols" 1964 y Betwixt and Between: the Liminal period in Rites de Pasaje" 1967).

URBANO, Osvaldo $\mathrm{H}$.

1974 "La representación andina del tiempo y del espacio en la fiesta". Allpanchis Phuturinga, 7, pp. 9-48. Cuzco.

VILLAGOMEZ, Pedro de

1919 Exortaciones e Instrucción acerca de las idolatrías de los indios del arzobispado de Lima. Col de Libros y doc. Ref. a la historia del Perú, vol. XII. Lima.

WASSEN, S. Henry

1972 a A Medicine-man's Implements and Plants in a Tiahuanacoid Tomb in Highland Bolivia. Etnologiska Studier 32. Goteborg.

1972 b Ethnobotanical Follow-up of Bolivian Tiahuanacoid Tomb Material and Of Peruvian Shamanism, psychotropic plant Constituents, and Espingo Seeds. Goteborgs. Etnografiska Museum. Astryck.

WILLEY, Gordon y John M. CORBETT

1954 Early Ancon and Farly Supe Cultura. Columbian Studies in Archeology and Ethnology, vol. III, Columbia University Press, Nueva York.

WILLIAMS LEON, Carlos

1972 "La difusión de los pozos ceremoniales en la costa peruana”. Apuntes arqueológicos, № 2, pp. 1-9. Lima.

YACOVLEFF, Eugenio y F.L. HERRERA

1935 "El Mundo Vegetal de los Antiguos Peruanos (conclusión)". Revista del Museo Nacional, T. IV, № 1, pp. 31-102. Lima. 